\title{
The evolution of research participant protections in South Africa
}

\author{
A Dhai, PhD, MB ChB, FCOG, LLM, PG Dip (Int Res Ethics) \\ Steve Biko Centre for Bioethics, Faculty of Health Sciences, University of the Witwatersrand, Johannesburg, South Africa
}

Corresponding author: A Dhai (ames.dhai@wits.ac.za)

South Africa (SA) has played a leading role in health research internationally. Ethical guidelines for the protection of research participants have been published by the Medical Research Council (MRC) as early as 1979. Ironically, the guidelines gave substantial prominence to the oppressive laws of the time. In its 4th edition of the guidelines, the MRC placed emphasis on SA needs, and incorporated the principles of the Bill of Rights of the SA Constitution 1996 into its guidelines. The most significant milestone in the history of participant protections in SA was the inclusion of research and experimentation in the Bill of Rights of the Constitution and the statutory legislation of protections in the National Health Act No. 61 of 2003.

S Afr Med J 2017;107(4):571-572. DOI:10.7196/SAMJ.2017.v107i4.12438

South Africa (SA) has played a leading role in health research internationally. SA's history in this context dates back to the 1800 s. The legislative basis for scientific research was first promulgated in 1945. However, there was then legislative and regulatory silence on protecting participants enrolled in research, and it was only about 60 years later that the National Health Act $^{[1]}$ (NHA) was promulgated, which prescribed clearly what the legal safeguards would be for participants in health research. Despite this legal hiatus, individual institutions and researchers drew from international norms and standards, and set up protective instruments for ethical oversight in health research. These efforts have been detailed in the previous issue of the series. ${ }^{[2,3]}$ This article describes the SA Medical Research Council's (SAMRC's) journey in guidelines development for participant protections, the protections in the Bill of Rights of the SA Constitution ${ }^{[4]}$ and the NHA, ${ }^{[1]}$ and concludes SA's journey in protecting the human dignity of participants enrolled in research.

The SAMRC research ethics guidelines ${ }^{[5]}$ In December 1979, the SAMRC published its first set of guidelines, entitled A Guide to Ethical Considerations in Medical Research, ${ }^{[6]}$ to safeguard the rights and welfare of human subjects involved in activities supported by grants or contracts from the council. The guidelines emphasised in the introduction that it was of paramount importance for any ethical code relating to medical research to err in the 'direction of stringency rather than laxity, and no man should find himself in the position of solely being judge of his own morals in research'. Ironically, substantial emphasis was placed on the oppressive laws of the time and the guidelines (also known as the Code) stated that: ${ }^{[6]}$

'The provision of this Code may not be construed in any manner or sense that would abrogate, supersede, or moderate more restrictive applicable law or precedential legal decisions.'

Furthermore, in its statement of principles, it was affirmed that institutions should adopt a statement of principles that would assist in their discharge of responsibilities for the protection of the rights and welfare of subjects. It went on to state that: ${ }^{[6]}$

'This official guide of the SAMRC may be used as a guideline for such a statement and care should be exercised to ensure that the principles outlined in the said statement do not supersede SAMRC policy or any legal rule.'

It was paradoxical that for the safeguarding of rights and dignities of participants, such importance was placed in the law, especially as this was in the context of the apartheid era where people of colour were oppressed and their rights abused. The Code's approach to minors illustrates quite aptly the MRC's strict adherence to the law. The stipulations of the then-Children's Act, No. 33 of 1960, were endorsed by the Code ${ }^{[6]}$ and parents would be the guardians of minors in research, with the father having the final say; however, where the child was illegitimate, its mother alone was its legal guardian. The document further stated that the position was more complicated where black Africans were concerned. Most 'Bantu' women were usually in the position of minors, and fell under the guardianship of their father or the head of the kraal if unmarried, and under the authority of their husband if married. ${ }^{[6]}$ The guardianship of a 'Bantu' child was difficult to establish, as SA law and the stateimposed Bantu law were in conflict on that point. A customary union was not recognised as a lawful marriage, according to SA law. This created uncertainty as to whose consent would have to be obtained for a child born in a customary union. It recommended that the consent of the legal guardian recognised by each system be obtained in order to avoid any problems that might have arisen from this uncertainty. ${ }^{[6]}$ Again, it is remarkable that the SAMRC placed such importance on the laws, especially considering there were two sets SA law and Bantu law. The latter applied to indigenous black South Africans, who clearly were not acknowledged as being on a par with others in the country. They were considered a lesser form of life, with no moral status or human dignity, and therefore did not qualify to benefit from the protections offered by SA law.

Eight years after the first edition, the SAMRC launched its Ethical Considerations in Medical Research. Revised Edition: 1987. ${ }^{[7]}$ There are no recorded external influences on the revised guidelines, and the reason given for the revision was that medical science was progressing at a rapid rate, and new ideas and questions that had not seemed to be significant just a decade back had become part of the ordinary problems that researchers had to deal with regularly. Of note is that the focus on complying with the legal framework was 
carried through into the second edition, although the term 'Bantu' was replaced with 'Black'. In addition, KwaZulu law was expanded upon for black women living in Natal, whose status upon acquiring majority at the age of 21 was no longer determined by a guardian. Moreover, the Kwa-Zulu Act on Medical and Surgical Treatment, No. 11 of $1986,{ }^{[7]}$ allowed for a married woman in certain circumstances to consent independently to treatment. The situation with regard to black children born of a customary union was also clarified. According to indigenous law, the consent had to be given by both the father and the head of the kraal. Where the child was illegitimate, consent had to be given by the mother and her legal guardian. The Code went on to state that these stipulations were valid only where the researcher and subject were both black. Where the researcher was not black, the ordinary principles of SA law were valid and the legal incompetence of black women according to traditional law did not apply. ${ }^{[7]}$ It is highly likely that these discriminatory distinctions between professionals created many tensions and conflicts, and even confusion.

With the promise of transition from apartheid to democracy just around the corner, the early 1990s in SA witnessed a flurry of activities towards change in laws and policies that took into consideration the rights and dignity of all South Africans. In the context of research, the Medical Research Act, No. 19 of 1969 was replaced by the MRC Act, No. 58 of $1991,{ }^{[8]}$ and the guidelines were further amended and replaced by Guidelines on Ethics for Medical Research - Revised Edition, 1993. ${ }^{\left[{ }^{[9]}\right.}$ Of note is that this set of guidelines made no reference to separate laws for black population groups and SA laws for other groups, as had been the case in the previous guidelines. The guidelines and laws referred to in this document applied to all South Africans equally, irrespective of colour. This is presumably because SA was on the brink of liberation and a democratic government.

Almost a decade after the SAMRC's 3rd edition of guidelines were published, the next set of revisions was issued in 2004. ${ }^{[10]}$ This was owing to a number of important factors, including major sociopolitical reform in SA, and great interest globally in the field of ethics in research, especially as a resurgence of transgressions around the world were being exposed. For its 4 th edition, the SAMRC placed emphasis on SA needs, and incorporated the principles of the Bill of Rights of the SA Constitution, 1996 into its guidelines. ${ }^{[4]}$ In addition, developing-country concerns were stressed.

\section{Participant protections in SA: \\ Law reform}

The most significant milestone in the history of participant protections in SA was the inclusion of research and experimentation in the Bill of Rights of the Constitution, ${ }^{[4]}$ and the statutory legislation of protections in the NHA. ${ }^{[1]}$ Section 12(2)(c) of the Bill of Rights, on freedom and security of the person, affirms everyone's right to bodily and psychological integrity, including the right 'not to be subjected to medical and scientific experiments without their informed consent'. Other protections for research in the Bill include the rights to equality (s 9), human dignity (s 10), life (s 11), and privacy (s 14).

For the first time in the history of SA, protections for participants in research were made mandatory by statutory law in 2003 , and so strong protectionism was mandated by legislation. Health research in terms of section 1 of the NHA includes:

'any research which contributes to the knowledge of -

- the biological, clinical, psychological or social processes in human beings;
- improved methods for the provision of health services;

- human pathology;

- the causes of disease;

- the effects of the environment on the human body;

- the development of new applications of pharmaceuticals, medicines and related substances; and

- the development of new applications of health technology'

This definition is very broad and covers a wide range of research activities, which, in terms of section 73 of the Act, will need to be reviewed by health research ethics committees that are registered with the National Health Research Ethics Council (NHREC). The establishment of the NHREC is provided for in section 72 of the Act. The function of the NHREC includes, among others, that of determining guidelines for the functioning of health RECs.

\section{Conclusion ${ }^{[5]}$}

The Nuremberg Code was the first international document in research ethics. It was established as a response to the disasters and disgrace in medical research generated by the Nazi doctors as highlighted in the previous article in this series. ${ }^{[3]}$ SA started establishing protections for participants of research from the late sixties. In SA, the protectionist approach was not as a response to scandals and tragedies inflicted on vulnerable participants by SA researchers, as it had been internationally, but because of a sense of moral agency, moral responsibility and moral accountability of researchers in this country towards the people they enrolled in research. SA researchers drew from Aristotelian and Hippocratic influences in their professional practice and embarked on the protectionist approach as a safeguard against atrocities and human dignity violations similar to the ones that Beecher ${ }^{3,11}$ described, especially because sponsors and researchers from well-resourced countries, and in particular the USA, had started finding less wellresourced areas highly attractive for the conduct of clinical research. SA researchers established protections for participants enrolled in research long before the legislative mandate to do so.

\section{Acknowledgements. None.}

Author contributions. Sole author.

Funding. None.

Conflicts of interest. None.

1. South Africa. The National Health Act No. 61 of 2003.

2. Dhai A. Health research and safeguards: the South African journey. S Afr Med J 2017;107(5):379-380. http://doi.org/10.7196/SAMJ.2017.v10715.12345

3. Dhai A. Exploitation of the vulnerable in research: Responses to lessons learnt in history. S Afr Med J 2017;107(6):472-474. DOI:10.7196/SAMJ.2017.v107i6.12437

4. South Africa. Constitution of the Republic of South Africa, Bill of Rights, Act No. 108 of 1996: s 36(1).

4. Douth Africa. Constitution of the Republic of South Africa, Bill of Rights, Act No. 108 of 1996: s $36(1)$. Dhai A. A study of

6. De V Lochner J. A Guide to Ethical Considerations in Medical Research. Parrowvallei: South African 6. De V Lochner J. A Guide to Ethical
Medical Research Council, 1979.

7. De V Lochner J. Ethical Considerations in Medical Research. Parrowvallei: South African Medical Research Council, 1989.

8. South Africa. Medical Research Council Act, No. 58 of 1991.

9. South African Medical Research Council. Guidelines on Ethics for Medical Research. 3rd ed. SAMRC: Cape Town, 1993.

0. South African Medical Research Council. Guidelines on Ethics for Medical Research: General Principles, 2002. http://www.mrc.ac.za/ethics/ethicsbook1.pdf (accessed 22 August 2013).

11. Beecher HK. Ethics and clinical research. N Engl J Med 1966;274(24):1354-1360. https://doi. org/10.1056/NEJM196606162742405

Accepted 17 March 2017 